\title{
Discussion on Basic Course of Modeling of Digital Media Application Technology Major in Higher Vocational Colleges-Case Study of Design Sketch
}

\author{
Yunke Wei
}

Guangdong Polytechnic of Science and Technology, Zhuhai Guangdong, 519090, China

Key words: Basic course of modeling, Modeling ability, Creativity, Multiplicity.

\begin{abstract}
Basic course of modeling refers to a required basic course covering "design sketch" and "three components". The research field of digital media application technology major is software interface design, requiring students to have certain fine arts foundation. The students of digital media application technology major of higher vocational colleges are non-art students who have no fine arts foundation. This paper is intended to analyze how teachers can guide students to overcome anxiety and develop an interest based on practical teaching experience, and put forward some practical methods of teaching of basic course of modeling of digital media application technology major.
\end{abstract}

\section{Introduction}

Basic course of modeling refers to a required basic course covering "design sketch" and "three components". For a long time, basic course of modeling has been focusing on sketch training. The generalized sketch refers to all unicolor drawings. The students of digital media application technology major of higher vocational colleges are non-art students who have no fine arts foundation. They touch the basic course of modeling upon entering college, so they are liable to become anxious and tired. How to turn boring traditional sketch course "interesting" and "useful", arouse students' initiative, and help students to overcome anxiety in practical teaching process is the focal point in this paper. The research field of digital media application technology major is software interface design, requiring students to have certain fine arts foundation. Design sketch is of great significance to non-art students for learning fine arts skills, exploring modeling rules, developing creative capability, and forming design capability. Since the examples given in teaching materials are obsolete, boring, unpractical, and unhelpful for cultivating students' creative, and over-stress structural perspective, they cannot satisfy the requirements and needs of digital media application technology teaching. In view of this, the writer intends to actively explore reform and innovation of basic course of modeling of digital media application technology major in higher vocational colleges in teaching practice of the course of design sketch. The personnel cultivating program of higher vocational colleges is to cultivate skilled personnel in a short period for mid-and-low-end computer drawing posts. The class hours of basic courses of modeling such as design sketch is short, and students have no foundation of fine arts. Thus, how to cultivate students' "modeling ability", "creativity" and "integration ability" in a short period is the focus of discussion in this paper.

\section{Discussion on Teaching Content of "Design Sketch" Course}

Based on experience in teaching of "design sketch" course for several semesters, the writer finds that design sketch is to observe objects and accept or reject picture from an artistic and scientific perspective, objectively depict objects with paper, pencil, drawing software, hand-painted plate, and such tools in accordance with artistic law, and design new artistic images for illustration and wallpaper, and so on with creativity and integration ability on the basis of objectively depicting objects. In teaching process, focus should be put on the cultivation of non-art students' "modeling ability", "creativity", and "integration ability". 


\section{Multiplicity of Objects to Be Shaped}

Traditional sketch course covers perspective, structure, and such content, for which gypsum sculptures or statues are usually used as painting objects. Interpretation of perspective and structure sketching theories and long-time traditional sketch training are carried out to train students' ability of traditional sketch modeling. The class hours of "design sketch" class in higher vocational colleges is short, only 4 class hours a week or 3 hours. Within the 3 hours, theory explanation and homework commenting and appraising will take half an hour. That's to say, students only have 2.5 hours for sketch practicing, which is even not sufficient for completing a sketch. Besides, digital media application technology belongs to the field of computer, and many colleges have no well-equipped sketch studio for classroom teaching. The limitations in class hour and teaching condition mean that students don't have good conditions for sketch practicing in class. Moreover, sketching gypsum sculptures or statues is boring and difficulty to those who have no foundation of fine arts. Thus, it is urgent to improve the teaching content. In view of this, the writer replaces gypsum sculptures or statues with "inanimate object", "motion object" and "figure" closer to life. To go from the easy to the difficult and complicated, simply-modeling fruit pictures (spherical fruits) will be employed first, then complicatedly-modeling dessert pictures will be employed, and animate objects such as plants and flowers follow. Students will be shown pictures of the same objects, and asked to draw one according to their interest. After the stage of inanimate object drawing, motion object drawing should follow. To this end, the writer will pick several pictures of birds, fishes and animals, and ask students to draw one according to their interest. The most complicated stage is figure painting. For this stage, students will be shown figure paintings, and asked to facsimile some paintings first, and then have drawing training and creation with classmates as model.

\section{Multiplicity of Painting Tools}

It is thought that traditional sketch only needs paper and pencil. The objective of personnel cultivation of higher vocational colleges is to cultivate skilled personnel. To reflect the objective of higher vocational education, design sketch teaching is carried out to cultivate professionals of computer drawing, and emphasize the cultivation of students' operational ability. There are multiple tools available for freehand or computer sketching. With paper and pencil, students can steel their freehand sketching skills, while computer drawing is helpful to train students' software operation ability. For selection of teaching aids, teachers should overcome their narrow consciousness, and introduce computer and such tools into teaching. The utilization of projector can greatly facilitate teachers in demonstration of painting process for students. With different painting tools, painting works of different styles can be produced. The existing mainstream painting tools can be classified into three categories: paper and pencil, paint software, and hand-painting plate. Paper and pencil include drawing pencil, sign pen, color pencil, etc. Paint software include Illustrator, Photoshop, etc. Every kind of painting tool should be interpreted from the aspects of method of application and steps of application in an illustrated way with examples. In classroom teaching, teachers should show how to use the painting tools. To this end, it is suggested to use computer drawing software, hand-painting plate, projector, and so on.

Before putting computer drawing software, hand-painting plate and projector into use for demonstration, it is suggested to explain how to observe objects and objectively express objects with the aid of hand-painting plate, as shown in Figure 1. To help non-art students to grasp sketching skills fast, it is suggested to explain the painting process in steps, and introduce structure and perspective theories, to depict the shape of objects accurately. Since the class hours is short, teachers should require students to grasp the shape of objects accurately only, namely structure sketching. 


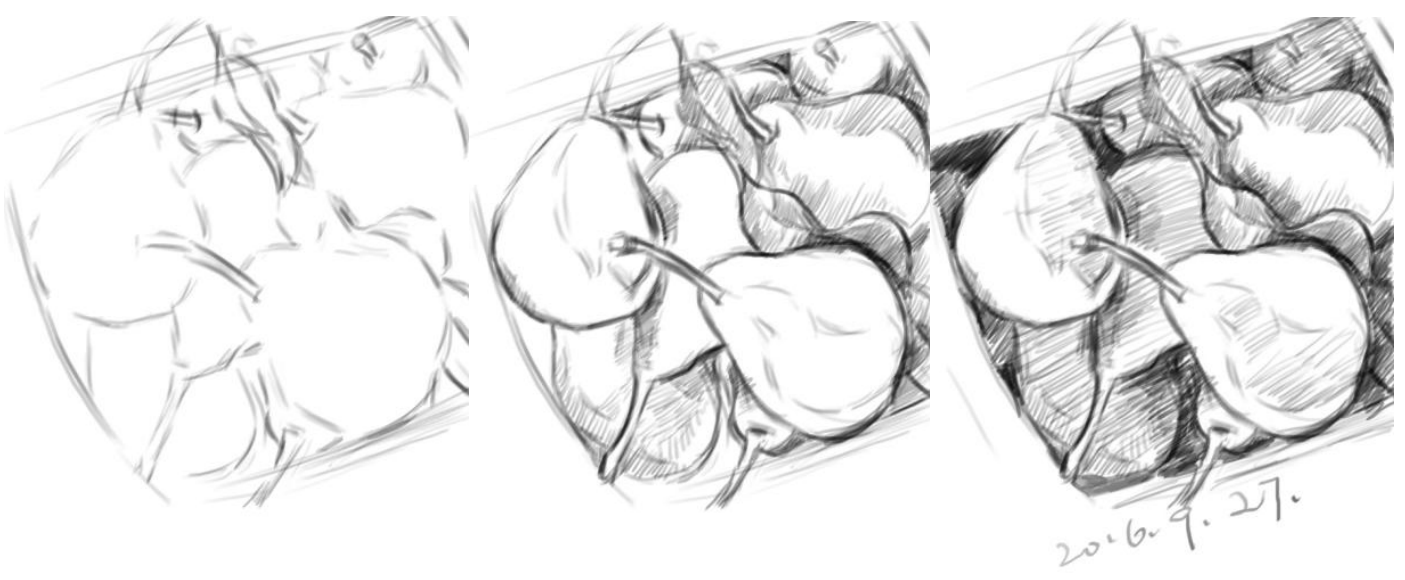

Fig. 1

After demonstration with the aid of hand-painting plate, teachers can complete paintings with drawing software such as Illustrator and Photoshop. In Figure 2, the left is a picture, and the right is a painting completed with drawing software. At the time of explaining painting skills, teachers also can explain the basic functions and operative skills of drawing software, such as pen tool, color filling, contour, layer style combination, brush, etc. Students also can use computer drawing software in painting to grasp more tools and improve their skills.
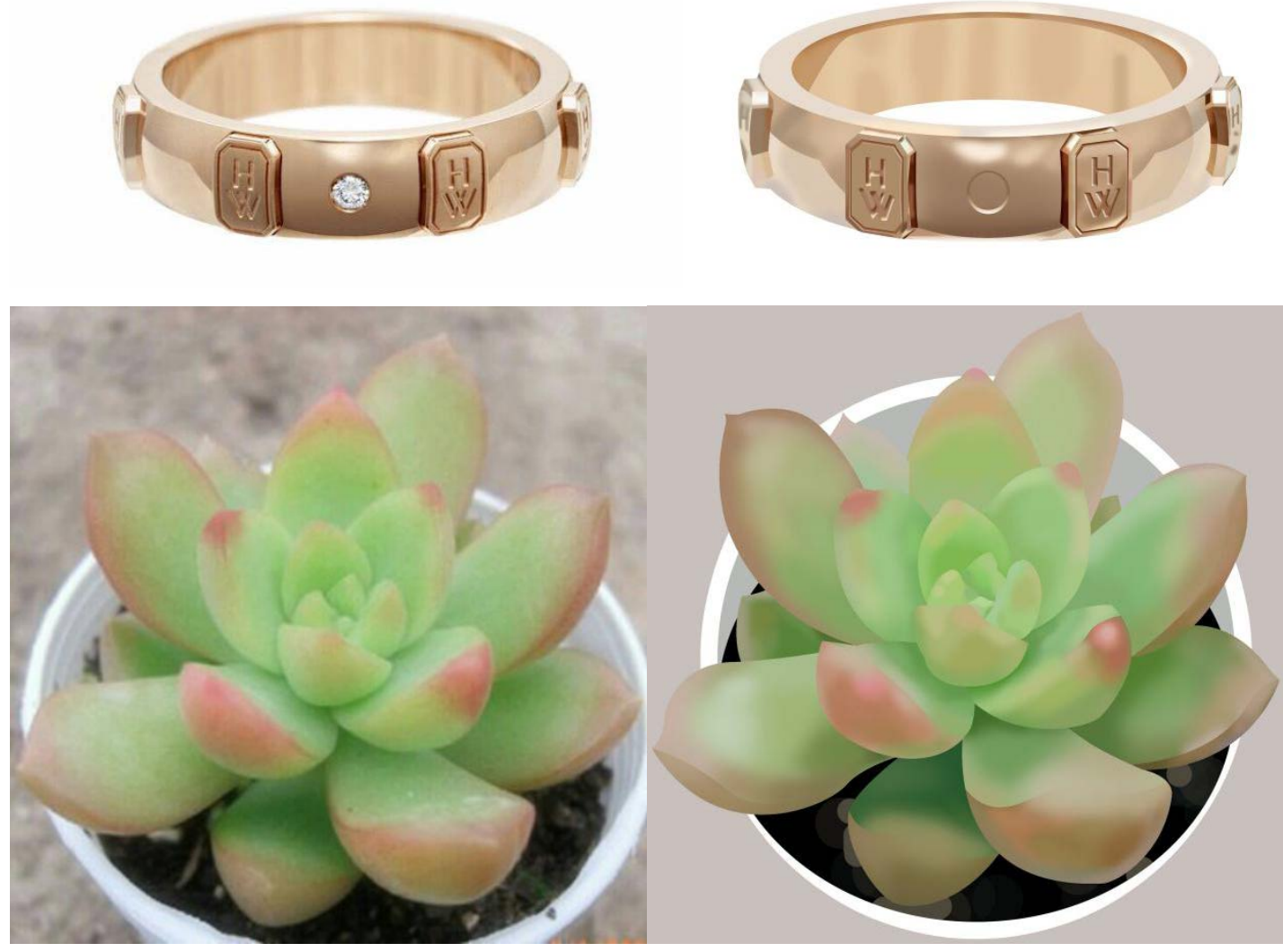

Fig. 2

\section{Inletting Design Content to Make Classroom Teaching Interesting}

Teachers should make greater efforts to psychologically guide non-art students, to help them overcome anxiety and arouse their interest in design sketch course. To achieve the objectives of the 
major and personnel cultivation, focus also should be put on the cultivation of students' creativity. Teachers can introduce wallpaper and illustration works of different styles, summarize the design rules and style characteristics of the works, and let students start from facsimileing and then make creation on this basis, to enhance the cultivation of students' creative thinking, as shown in Figures 3 and 4. Students cannot copy examples completely, but use the examples for reference only. In Figure 3 , the left is a cartoon of fruit. Students should break the mindset, and don't limit to "fruit", but make creation with other types of inanimate objects. The right in Figure 3 is a cartoon moon created by the writer by referring to the cartoon fruit on the left. The pictures share something in common, that's people's five sense organs and expressions are used in inanimate objects to vitalize them and convey an emotion of pleasure. The left in Figure 4 is a wallpaper with patters of cartoon animal, and the right is a wallpaper created by the writer according to the characteristics of the left. The characteristics of the pictures are that the facial features of animal are extracted, a unicolor picture is presented, and it is allowed to add texts to enhance the theme. Through learning and exercise, students can learn to draw practical pictures, but also make design of inanimate objects and motion objects by means of "grafting" or exaggeration, to make the objects funny and interesting. Teachers should encourage students to refer to the available wallpapers and illustrations, because students will devote themselves to learning with greater enthusiasm once they find the learning and exercise are useful.
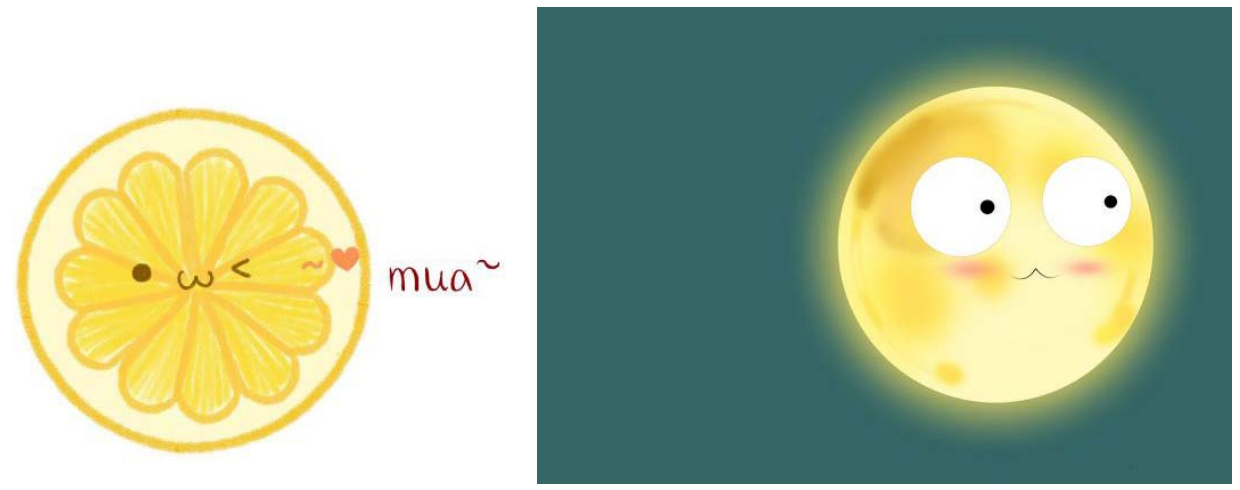

Fig. 3

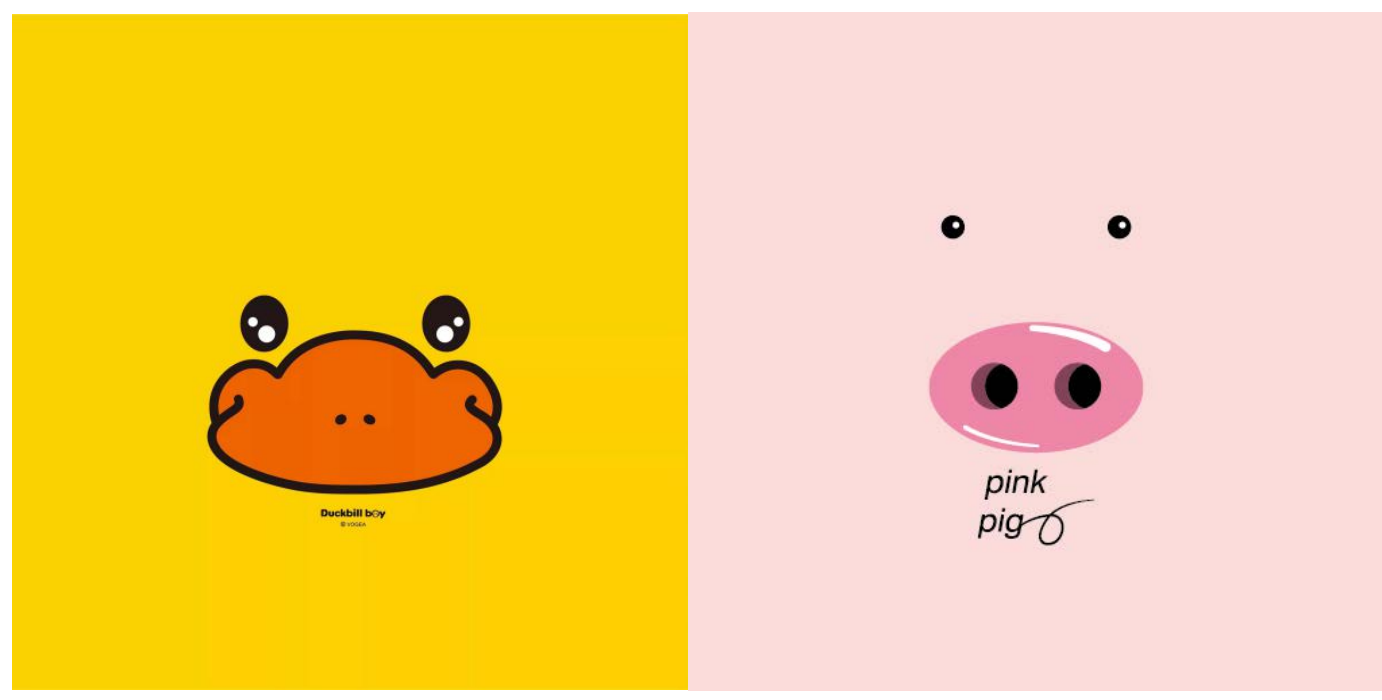

Fig. 4 


\section{Cultivating Students’ Competitive Spirit by Holding Skill Competition or Works Exhibition}

Competition is to strive for excellence and cease to be insipid. Competitive spirit can rouse people, and push people to work hard. It is indispensable for individuals, groups, and states for development in modern society. Only those who have competitiveness have vitality, can make fast progress, and finally realize their ideals.

To adapt to the rapidly developing society, teachers, in the process of talented personnel of digital media application technology major of higher vocational colleges, should help students to develop competitive spirit by holding skill competition or works exhibition to arouse students' initiative, encourage students to display their learning outcomes, show their capabilities, learn about students' learning level, and identify problems. Skill competition or works exhibition can start with basic courses of modeling such as design sketch, and then extend to other digital media application technology courses. Besides, skill competition or works exhibition also are helpful to promote the relationship between teachers and students and among teachers, and temper their ability of planning and organizing. Through communication, teachers and students can draw on each other's strength.

\section{Conclusion}

Digital media application technology major belongs to the field of computer, and the students all are non-art students who have no foundation of fine arts and are bound to be nervous, anxious and lost in the basic courses of modeling such as design sketch. Thus, teachers should make such basic courses of modeling like design sketch funny and interesting through curriculum design and teaching process, to arouse students' interest, cultivate students' competitive spirit, and encourage students to overcome themselves and work hard. In this way, students will continuously grow through learning and practice, and lay a sold foundation for follow-up learning and future development.

\section{Acknowledgement}

This paper is used for the sponsorship of the "Class 1 Brand Major of Higher Vocational Education in Guangdong Province" (Project No.: 2016gzpp007), the "Brand Major Construction Project of Higher Vocational Education in Guangdong Province", the 2014 Guangdong Province Higher Vocational Education and Teaching Reform Project (Approved) (Project No.: 201401091), the Excellent Young Teacher Training Plan Program of Colleges and Universities in Guangdong Province (Project No.: yq2014187), the 2015 Reform Project of Guangdong Provincial Information Technology Educational Instruction Committee: Curriculum Design of Industrial Software International Programming Standard for Computer Major, Teaching Reform Project of Guangdong Polytechnic of Science and Technology (No.: JG201505): Industrial Software Course Design Based on IEC61131-3 International Industrial Programming Standard.

\section{References}

[1] Feng Bingmei. Primary Exploration of Reform of Basic Courses of Modeling of Art Education, Art Panorama, 2008(9):154.

[2] An Bin, Selection of and Thinking on Modern Modeling Fundamental Teacing Mode-Case Study of Practice of Basic Teaching of China Academy of Art, Journal of Hubei Institute of Fine Arts, 2009, 27(1):72-77.

[3] Pei Zhefeng. Thinking on Teaching of Basic Course of Modeling of Artistic Design Major, Education and Vocation, 2007(3):116-117.

[4] Qiu Xiaohong. Study on Cultivation of Non-art Students’ Basic Modeling Ability, Science \& Technology Information, 2008(23):594-595. 
[5] Wang Zhi. Construction and Practice of Teaching System of Basic Course of Modeling of Fine Art Major, Journal of Beijing Film Academy, 2010, 2010(4):59-65.

[6] Li Li, Zhang Yan, Discussion on and Practice of Basic Course of Modeling of Artistic Design Major, Zhuangshi, 2012(8):104-105. 